Portland State University

PDXScholar

8-11-1994

\title{
Children's Conception of the Social and Moral Dilemmas Associated with Drug Use
}

Nancy Lynn Thayer

Portland State University

Follow this and additional works at: https://pdxscholar.library.pdx.edu/open_access_etds

Part of the Child Psychology Commons

Let us know how access to this document benefits you.

Recommended Citation

Thayer, Nancy Lynn, "Children's Conception of the Social and Moral Dilemmas Associated with Drug Use" (1994). Dissertations and Theses. Paper 4852.

https://doi.org/10.15760/etd.6728

This Thesis is brought to you for free and open access. It has been accepted for inclusion in Dissertations and Theses by an authorized administrator of PDXScholar. Please contact us if we can make this document more accessible: pdxscholar@pdx.edu. 


\section{THESIS APPROVAL}

The abstract and thesis of Nancy Lynn Thayer for the Master of Science in

Psychology were presented August 11, 1994, and accepted by the thesis committee and the department.

COMMITTEE APPROVALS:

Janice Haaken, chair

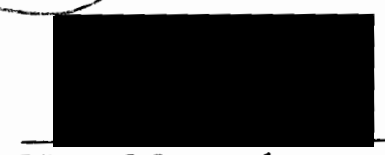

Hugo Maynard
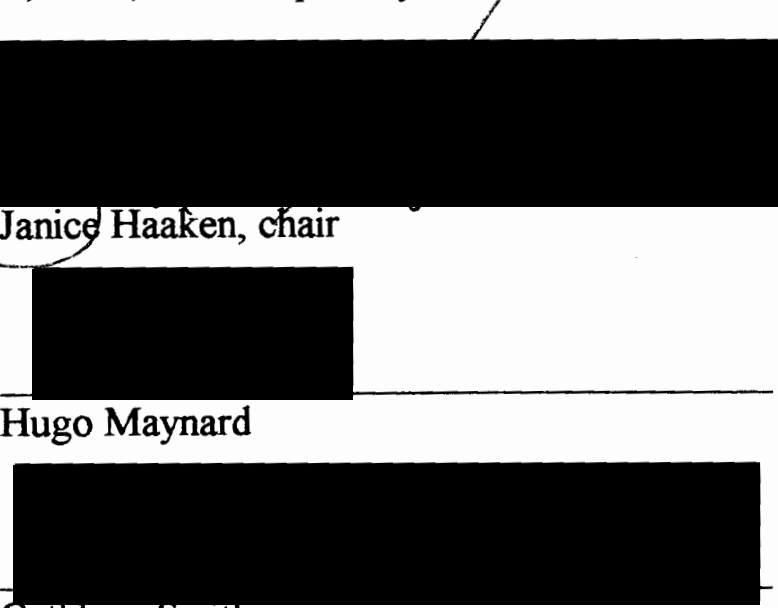

Cathleen Smith

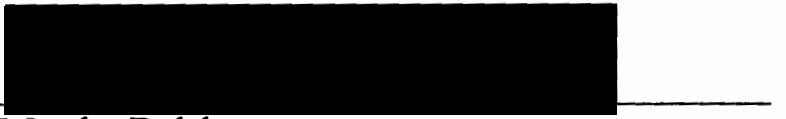

Martha Balshem

Representative of the Office of Graduate Studies

DEPARTMENT APPROVAL:

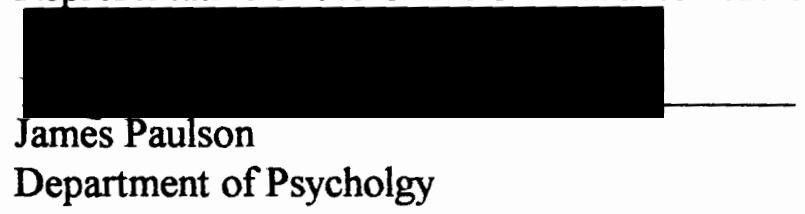

\section{ACCEPTED FOR PORTLAND STATE UNIVERSITY BY THE LIBRARY}

by

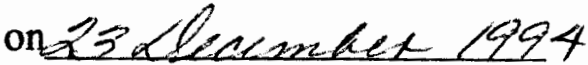




\begin{abstract}
An abstract of the thesis of Nancy Lynn Thayer for the Master of Science in Psychology, presented August 11, 1994.
\end{abstract}

Title: Children's Conceptions of the Social and Moral Dilemmas Associated with Drug Use.

The use and abuse of drugs among adolescents and adults has prompted a renewed national concern about drug abuse. Educational programs have attempted to provided factual information and create negative attitudes about drug use so that students will decide not to use drugs. Studies have revealed, however, that the drug programs have not been effective in reducing drug use.

The present research addresses two primary questions: 1) Are there developmental differences in young persons' perceptions of social and moral dilemmas associated with drug use? and 2) Are gender and race associated with social and moral reasoning about drug use?

Semi-structured interviewers were conducted with 32 fourth and 32 eleventh grade students. The interview posed two vignettes about drug-related behavior, including helping behavior. In addition, the interview probed respondents' conceptions of the problems associated with drug use and of the treatment that users and dealers should receive. Content analysis produced 40 codes which reached the reliability criterion of 60 percent agreement. The Kappas ranged from .57 to $.91(\underline{m}=$ .66). Chi square tests were conducted, using the variables of race, sex and the thematic categories associated with each question. 
Of the 26 tests of significance conducted on the variables, two were significant for grade, two were significant for gender and one was significant for race. Eleventh grade students were more likely to specifically reject some category of help than the fourth grade students $(\chi 2=4.48, p<.05, d f=1)$. Fourth grade students were more likely to consider teachers as a source of help $\left(\chi^{2}=3.48, p<.06, d f=1\right)$. Female students were more likely to acknowledge risk to themselves due to helping ( $\chi 2=$ $4.27, p<.04, d f=1$ ). Caucasian students were more likely to acknowledge that there may be risks to the helpee due to helping $\left(\chi^{2}=3.52, p<.06, d f=1\right)$. Male students were more likely to want punishment and control of drug dealers $(\chi 2=5.32, p<.05$, $d f=1)$

In general, the findings indicate that there are fewer developmental, gender and race differences in children's perception of drug use and associated dilemmas than might be expected. Students' descriptions did reveal that they are thinking and reasoning about the information given to them. 
CHILDREN'S CONCEPTIONS OF

THE SOCIAL AND MORAL DILEMMAS

ASSOCIATED WITH DRUG USE

by

Nancy Lynn Thayer

a thesis submitted in partial fulfillment of

requirements for the degree of

MASTER OF SCIENCE

in

PSYCHOLOGY

Portland State University

1994 


\section{ACKNOWLEDGMENTS}

Many thanks to the following persons for helping me complete to this project:

To my advisor and thesis chair, Dr. Janice Haaken and to my thesis committee, Dr. Cathleen Smith, Dr. Hugo Maynard, and Dr. Martha Balshem, for their time and suggestions.

To Janet Gillman, for serving as an interviewer.

To Caroyn Wright, for transcribing the interview tapes.

To the coders and student assistants for the study, Shawn Bacon, Linda Brownlee, Joanna Bulkley, Tonya McCollum, Erica Storm, and Ron Yoder, for their hard work.

To the children and adolescents at the participating schools who served as respondents.

To Dr. Thomas Kindermann for his advice and for the use of his lab.

To Kathy Kiwala and Julie Reynolds-Kwee for their advice, support, and friendship.

To Brett Casper for his help with the development of the study, interviewing, coding, and for his advice and companionship throughout the entire process.

To my parents, Lois and Steve Thayer. 


\section{TABLE OF CONTENTS}

$\begin{array}{ll}\text { INTRODUCTION } & 2\end{array}$

Moral Developmental Theories $\quad 4$

Sex Differences In Moral Development 7

Children's Conceptions of Drug Use 10

$\begin{array}{ll}\text { Ethnic Differences } & 12\end{array}$

$\begin{array}{ll}\text { METHOD } & 14\end{array}$

$\begin{array}{ll}\text { Subjects } & 14\end{array}$

$\begin{array}{ll}\text { Instrument } & 15\end{array}$

$\begin{array}{ll}\text { Procedure } & 17\end{array}$

$\begin{array}{ll}\text { Analysis } & 18\end{array}$

$\begin{array}{ll}\text { RESULTS } & 19\end{array}$

$\begin{array}{ll}\text { DISCUSSION } & 27\end{array}$

Limitations 31

Future Research $\quad 32$

$\begin{array}{ll}\text { Conclusion } & 32\end{array}$

$\begin{array}{ll}\text { REFERENCES } & 34\end{array}$

$\begin{array}{ll}\text { APPENDIX } & 39\end{array}$ 


\section{INTRODUCTION}

The use and abuse of drugs among adolescents and adults has prompted a renewed national concern about drug abuse. One of the primary agendas of the current "war on drugs" has focused on public education's role in shaping the values of children. Some educational programs have attempted to provide factual information so that students can decide not to use drugs (Thompson, 1978; Moskowitz, Schaps, Schaeffer, \& Marlin. 1983). Other programs have attempted to create negative attitudes toward the use of drugs (Goodstadt \& Sheppard, 1983; Braught \& Braught, 1984). Studies have suggested that drug and alcohol programs in the schools are not effective in reducing drug and alcohol use in youth (Tobler, 1986; Mauss, Hopkins, Wisheit, \& Kearney, 1988). Further, Tobler (1986) contends that there is evidence that increased knowledge about drugs can be associated with increased drug experimentation. Moskowitz (1989) has also concluded that programs which increase knowledge have rarely been accompanied by changes in attitude or drug using behavior. The programs therefore need to do more than supply information if they are to reduce drug use among youth.

Programs such as Project Smart (Hansen, Johnson, Flay, Graham, \& Sobel, 1988) have had success using structured curriculum and exercises to improve decision-making skills about drug use. Recent findings, however, raise questions about the longevity of the gains that are achieved (Moskowitz, 1989). Such findings document the limits of changing a complex behavior by intervening at one point in the process (Pentz, Dwyer, Mackinnon, Flay, Hansen, Wang, \& Johnson, 1989).

Researchers are now presenting arguments for approaches to drug education which do not rely on the use of scare tactics in order to be effective. Forbes (1987) 
argues that the current drug scare has intensified the social control functions of public education and has reinforced assumptions that drug problems are the result of individual characteristics. Social control, according to Forbes, refers to the role of institutions in controlling human behavior and therefore reducing threats to the social order. Examples of such institutions include the juvenile court, psychiatric clinics, social work agencies, and public schools. Glassner and Loughlin (1987) propose that drug use among adolescents has been overemphasized as a cause of the adult world's loss of control and anxiety over societal pathologies. Programs have focused on adolescent delinquency as a precursor to adult problems in adjustment. This focus is based on the belief that adolescents are the problem and ignores the possibility that underlying societal problems contribute to the delinquency.

In terms of drug use, prevention programs have the aim of reducing drug use, an outcome which presumably improves school performance and participation in constructive activities. Prevention of drug abuse then is seen as contributing to a decrease in antisocial behavior and an increase in the number of productive citizens. Drug users are viewed as people with a "lack of social competence" who need to be taught individualized social skills. In other words, drug prevention professionals tend to view the problem as a disease that is "located within individuals rather than their relations to unstable or exploitive social and economic environments" (Dixon, 1984). Forbes (1987) agrees that the current drug scare prompts assumptions in drug education programs that drug problems are a result of aspects of individuals.

While the goals of prevention programs which focus solely on the individual may be helpful to some, these programs make assumptions which underestimate the complexity of the etiology of drug use. Forbes (1987) feels that this individualistic approach ignores how the hierarchies of class, sex, and race are integral to a 
person's experience and to drug use.

In order to inform effective drug education programs, research needs to focus on the larger conceptual framework and social context of drug use. Individual approaches have been found to have limited impact on reducing drug use (Moskowitz, 1989). Although research has investigated factors such as social adjustment and self-esteem in relation to drug use among youth, a more detailed understanding of how children incorporate the information that they receive concerning drugs is needed.

Research which investigates how children and adolescents reason when faced with moral dilemmas may be relevant to understanding the cognitive processes individuals use in incorporating drug-related information. A moral dilemma is a situation which confronts the subject with two or more choices suggesting that one choice violates one set of moral precepts and the alternative choice violates another. The subject's choice and his or her reasoning in support of that choice are assessed to determine the stage or type of moral reasoning applied.

The present study explores developmental differences in children's understanding of drug use. The study examines responses of fourth and eleventh grade youths to structured interview questions which probe social-cognitive dimensions of drug use, including moral dilemmas relating to drug use and abuse. The primary goal of the research is to investigate developmental differences in children's perceptions of the social and moral dilemmas associated with drug use. Related questions concern the association of gender and race with social and moral reasoning about drug use. Moral Developmental Theories

Kohlberg $(1963,1969,1985)$ is the major theorist who has studied the moral development of children. Kohlberg formulated three broad levels of moral 
development each subdivided into two stages. Classification into stages is based on subjects' reasoning and justification for their actions in response to hypothetical moral dilemmas. When assigning a stage, the researchers determine whether the subjects justify decisions based on obedience to rules and authority, selfish needs, or the need of others. The order of the stages is presumably fixed but the stages are not acquired at the same age for all persons. Kohlberg believes that the stages are determined by cognitive abilities of individuals. Once one stage has been attained, the theory predicts that a person cannot regress to an earlier stage. The theory therefore assumes that morality is not situation specific. The theory also assumes that the sequence of stages should be invariant across cultures, although age of acquisition may vary considerably.

Researchers have argued that moral judgments and moral behavior are often unrelated, especially in young children (Blasi, 1980, 1983). Burton (1984) proposes that behavior is often impulsive and is not always the result of rational thought. Leming (1978) has concluded that older children are more likely to behave in accordance with their moral reasoning, whereas younger children exhibit discrepancies between moral reasoning and moral action.

If these findings are accurate, drug education programs should have different objectives depending upon the age group that is being addressed. Programs which reach older children may be effective if they are able to modify moral reasoning about drug issues, but young children may require a very different approach. Exploratory research like the present study may suggest important developmental differences between age groups which affect modification of moral reasoning associated with drug behavior. 


\section{Real verses Hypothetical Dilemmas}

The most commonly used research method in assessing moral development involves the analysis of subjects' responses to a series of hypothetical dilemmas that elicit a narrative response. Critics of this approach, such as Baumrind (1978), have argued that the approach has limited generalizability. The concern is that such dilemmas focus on unfamiliar issues which are difficult for people to identify with and which do not elicit an emotional response. (Walker, DeVries, \& Trevethan, 1987). Walker (1989) similarly emphasizes that the nature of the task is critical in assessing moral orientation. Walker believes that is important to use real-life dilemmas as opposed to standardized tasks such as fables.

Carol Gilligan (1982) also argues that realistic and potentially personal dilemmas are more valuable than the imaginary, hypothetical questions posed in Kohlberg's studies. Gilligan and Belenky (1980) report data on the relationship between hypothetical and real-life dilemmas in their study of women considering abortion. They found that over $40 \%$ of the subjects engaged in higher moral reasoning on the real-life, or realistic, dilemma than those presented with the hypothetical dilemma. Gilligan and Belenky believe that the discrepancies are not due to measurement error but are due to actual differences in cognitive processing between the two types of dilemmas.

Gilligan and Belenky (1980) conclude that the use of hypothetical dilemmas is not adequate to capture the highest level of moral competence for many individuals. Therefore, a real-life dilemma is more likely to provide relevant information about how a person will actually react in situations which require moral reasoning. A unique aspect of the Gilligan and Belenky study is that subjects were asked to define moral problems and what experiences they considered to be moral conflicts in their 
lives. Examining people's interpretations of morality in this way will help psychologists to represent and more clearly understand moral development and moral conflict.

\section{Sex Differences in Moral Development}

Carol Gilligan (1982) proposed that males and females differ in their basic social orientation and that this difference extends to conceptions of morality. Gilligan defines moral orientation as a conceptually distinct perspective for organizing and comprehending moral issues. She developed a theory which describes how men and women differ in their moral orientations. Gilligan believes that men are more likely to have a "justice" or "rights" orientation and therefore to view morality as involving issues of conflicting rights. Her theory also states that women are more likely to have a "care" orientation. Gilligan believes that the care orientation develops from women's tendency to be sensitive and concerned for the well-being and care of others. Women tend to view morality as involving issues of conflicting responsibilities. Men, on the other hand, tend to have a more individualistic conception of the self and to value objectivity and impartiality rather than sensitivity toward others.

Gilligan criticized Kohlberg's theory of moral development because he based his theory primarily on male samples. She believed Kohlberg's system of scoring moral development was biased against women because it did not take gender-based moral orientation into account.

While many researchers have failed to find significant sex differences in moral reasoning (Walker, 1984, 1986; Ford and Lowery, 1986), Lyons (1983) produced results which support Gilligan's theory. Lyons asked individuals of all ages to discuss their own "real-life" moral dilemmas. The interviews were analyzed by 
looking for themes concerning rights and care issues. Lyons found that care considerations were predominant for $75 \%$ of females and rights considerations were predominant for $79 \%$ of males. Walker, DeVries, and Trevethan (1987) argue that Lyon's results may be due merely to differences in the types of moral problems that men and women encounter or consider as a problem. The Walker, DeVries, \& Trevethan (1987) study attempted to produce data which would clarify the relationship, but they found very inconsistent results.

In a study of real-life dilemmas of adolescents and adults, Gilligan and Attanucci (1988) reported gender-linked patterns. Women were more likely to show a care focus and men were more likely to show a justice focus. Johnston, Brown, and Christopherson (1990) also found gender related differences in the moral conflicts of adolescent boys and girls in a private school setting. Their results showed that although both boys and girls often described real life moral conflicts in the context of a relationship, boys were more likely than girls to focus on themselves. Girls were more apt to focus on concerns about the relationship rather than on concerns about themselves.

The present study provides more data about sex differences in moral development by posing drug related moral dilemmas which are chosen by the researchers and are presented in a standardized way to all subjects. The dilemmas are "real-life" dilemmas in that they are situations which the subjects may encounter at some time during childhood or adolescence and are topics that are likely to be discussed at school, at home, and with friends. Since the dilemmas are not selfgenerated, the findings may not reveal gender differences, but the study may be able to clarify discrepancies in the literature.

Another issue which the proposed study addresses is the developmental patterns 
of sex differences. Since the nature and extent of sex differences in moral development remains controversial, it is difficult to predict how sex differences change over the life span. Gilligan (1982) and Langsdale (1986) both report that sex-related moral orientations are evident across the life span. Langsdale (1986) analyzed moral orientations expressed in response to Kohlberg-type hypothetical dilemmas and a hypothetical abortion dilemma. Differences in sex-related moral reasoning over the life-span were established in both studies by comparing the responses of children, adolescents, and adults.

Boldizar, Wilson, and Deemer (1989) used a standardized moral reasoning test (Defining Issues Test) to study subjects over a ten year period from high school to young adulthood. Their findings indicated that men and women did not differ in adult levels of moral reasoning. They did, however, find that the sexes differed in the predictors that determined moral judgment development in adulthood. For example, career fulfillment was the most powerful predictor of moral development in men but not in women. In other words, having a meaningful career produced a strong effect on the Defining Issues Test scores for men only. Marriage had a significant negative effect on DIT scores for women, but no effect on men's scores. This suggests that sex roles which are carried out over the lifetime do affect moral reasoning, despite evidence that actual levels of moral development do not differ between the sexes. The authors believe that the research supports Gilligan's (1982) argument that developmental theories of morality must work to understand and incorporate the life experiences of women as well as those of men. Boldizar et al. (1989) believe that although women are not morally "inferior" to men when assessed with Kohlberg type measures, their experiences do make very different contributions to their development. 
While the present study does not address the developmental process throughout the life span, it does compare sex differences in two age-based samples, i. e. preadolescence and middle adolescence samples. Since the present study is investigating drug-related moral dilemmas, sex differences in children's attitudes toward drug use must be considered. A study by Pascale, Trucksis, \& Sylvester (1985) is one of very few studies which investigates children's attitudes about drug use and which attempts to account for variables affecting those attitudes. The major finding was that more females than males perceived a need for a school-based drug program. Although the study did not specifically address moral reasoning, the findings may suggest that pre-existing sex differences in conceptions of drug use can account for sex differences in moral reasoning processes regarding this topic. The present study will consider the factor of sex differences in conceptions of drug use.

\section{Children's Conceptions of Drug Use}

Although research that directly asks children about their conceptions of drug use is limited, several studies have explored children's understanding of drug-related issues. A study by Carpenter, Glassner, Johnson, and Loughlin (1988) asked subjects from 12 to 20 years old to answer questions about the relationship between drugs and crime. The authors cited a statistical relationship between drugs and crime and wondered how children perceive the association, hypothesizing that children produce theories from broad cultural beliefs and from their own experiences and observations. Results revealed that youth who were not involved in drug use tended to talk about the association in stereotypic terms which emphasized the irrational behavior that results from drug use. Their responses also tended to be brief and lacking in complexity. Youths who were more involved with drug use drew on their own experiences to interpret the association. They tended to view 
drug use as resulting in impulsive behavior and thus indirectly contributing to crime. The most criminally involved subjects agreed that drug use indirectly leads to crime, but often denied that there was such a connection in their own case. They reported being impulsive at times, but never out of control. The results of the study suggest that varying views about the relationship between drugs and crime reflect the different experiences available to categories of youths.

Another study by Mohr, Sprinthall, and Gerler (1987) examined adolescent thinking as it relates to judgments about drug abuse. The researchers compared the level of moral reasoning on "close to home" social dilemmas about drug use to level of reasoning on more abstract dilemmas which are removed from daily living. Researchers also compared sex differences in level of reasoning when resolving drug-related dilemmas. The results indicated that middle school students tended to demonstrate higher levels of moral reasoning when confronted with abstract social dilemmas which are not close to their experiences than when confronted with drugrelated dilemmas which may be "close to home". The authors did not specifically discuss possible explanations for the differences in moral reasoning but did imply that the subjects were inexperienced with reasoning about drug-related dilemmas and therefore could not use higher-level reasoning. Another finding was that adolescent girls tended to reason at higher levels on drug-related dilemmas than did boys. The boys' level of reasoning declined more than the girls' in reaction to more personal dilemmas. This indicated that there is some type of interaction between sex and content of dilemmas. The authors did not speculate about the sex interactions, but instead discussed the implications sex differences for designing prevention programs. The authors cautioned that the sex differences may be unique to early adolescence because the sexes may not be starting at the same cognitive level at that 
age. If boys and girls in the eighth grade are not at the same cognitive level, the differences due to content of dilemma may be overestimated. Therefore, replication with different age groups is needed.

Ethnic Differences

The present study also examines ethnic differences in children's reasoning about drug use. Ethnicity can be a factor in both moral reasoning studies and drug prevalence studies. Tucker and Locke (1986) found a difference in the level of reasoning of subjects on moral dilemmas by altering the ethnic identification of the protagonist in dilemmas. Ethnicity is therefore one of the elements which interacts with the content of dilemmas. The existence of a care and responsibility ethic, as proposed by Gilligan (1982), is one example of a factor which could be considered in resolving ethical dilemmas across cultures. Harding (1987) cites parallels between feminine and African world views and associates the ethic of caring with the altruistic philosophies of African culture. Moral reasoning would then be associated with ethnic background and sex.

Newcomb and Bentler (1985) propose that modeling of a specific behavior by peers and adults is an important influence on adolescents' behavior. This is another way in which ethnic background can produce differences in reasoning about drug use. Differences in the patterns of behavior between ethnic groups can lead to differing perceptions about drugs and therefore influence moral perceptions of drug use. The present study examines response patterns of African American and Caucasian students from inner-city schools.

In summary, this study explores responses of fourth and eleventh grade youths to structured interview question which probe social cognitive dimensions of drug use, including moral dilemmas relating to drug use and abuse. The present research will 
address two primary questions: 1) Are there developmental differences in young people's perceptions of social and moral dilemmas associated with drug use? 2) Are gender and race associated with social and moral reasoning about drug use? 


\section{METHOD}

\section{Subjects}

Subjects were 32 fourth grade students and 32 eleventh grade students $(N=64)$. (See Table 1 for display of sample) Grade school and high school students were recruited from schools in Northeast Portland. The schools which were chosen are thought to have comparable demographic composition, have exposure to similar drug cultures, and have been the target of similar anti-drug campaigns. A description of the purpose and procedure of the study was presented at several classrooms for each grade level. The classrooms were chosen by the principals of the schools. Each student received a description of the study, a consent form, and a letter from the school principal inviting participation and expressing support for the study. Written consent was sought from participating subjects and their parent or guardian (See Appendix A for Consent Form). Confidentiality and protection of identity were guaranteed to participants. Subjects were assured that their responses would not be shared with teachers nor would refusal to participate negatively affect their relationship with their teacher or school. The pool of volunteering participants was divided according to specific demographic characteristics, i.e., male, female, and African-American, Caucasian. Subjects were then randomly selected from that pool. 
Table 1: Ethnicity, Gender and Grade level of Participants (Entries are n's)

4th grade 11 th grade

African American

Female

8

8

African American

Male

8

8

Caucasian

Female

8

8

Caucasian

Male

8

8

\section{Instrument}

The instrument used to measure conceptions of drug use is an open-ended interview schedule which was developed at Portland State University by Janice Haaken, Ph.D., with input from Brett Casper and Nancy Thayer, Psychology graduate students who are part of the research team (See Appendix B for a copy of the interview schedule.) The interview is designed to survey respondents' conceptions of terms such as "drugs," "drug abuse," and "drug addict" and opinions about the risks of drug use. The interview also probes conceptions of legal and social issues related to drug use as well as conceptions of the relationship between drug use and peer relations. In addition, the interview poses specific moral 
dilemmas associated with drug use and probes the moral reasoning behind subjects' responses.

A pilot study was conducted to evaluate the interview schedule. The interview was conducted with four primary school-aged and four high school-aged students from Northeast Portland. A content analysis of transcribed interview data allowed a refinement of the interview schedule. Some questions were omitted or modified based on subjects' comprehension of questions and the extent to which questions elicited varied and substantive responses. Modifications were also made in the sequence of questions and in the length of the interview schedule. Analysis of the pilot data also prompted new questions and probes to be added.

The interview begins with two vignettes about drug-related moral dilemmas. The subjects were asked how the characters in the vignettes should respond to the dilemma and why they should respond in that way. The gender of the protagonist was varied to match the gender of the respondent. In addition to specific moral vignettes, the interview probes for respondents' conceptions of drugs as an organizing category for thinking about danger and risk (e.g., "Do you think there is a drug problem in your community or the country?" "Why do you think people take drugs?" "How much do people have to use drugs to have a problem?") A second area probes respondents' conceptions of legal and social issues regarding drug use (e.g., "Why do you think certain kinds of drugs are against the law?" "Do you think that any of the drugs that are illegal now should be made legal?" "How do you feel about the way police treat people with drug problems?") A third area probes conceptions of moral issues associated with drug use (e.g., "Is it wrong to use drugs?" "How do you think people with a drug problem should be treated?" "Do you think parents should be told if their teenagers try drugs?") A fourth area probes 
conceptions of the relationship between drug use and gender, ethnicity, and socioeconomic status (e.g., "Are certain people or groups of people shown to take drugs more than others on television or the movies?" "Are there any differences in how much boys and girls use drugs?" "Do you think rich kids and poor kids take drugs for different reasons?")

\section{Procedure}

Formal consent for the study was granted by the Research and Evaluation office of the Portland Public Schools. The principal of each school suggested appropriate classrooms for participation in the study based upon the most likely classes that all of the fourth and eleventh grade students would be attending.

The four members of the research team met classroom teachers individually to explain the purpose and procedures of the study. The team and one of the two graduate students presented a brief description of the study in selected classes, and invited students to participate. Students were then given a description of the study, the consent form, and the letter from the school principal inviting participation and expressing support for the study. Written consent was required from volunteering students and from their parents. Approximately 53\% of the students who heard the presentation volunteered and returned content forms. Volunteer students were divided according to specific demographic characteristics and then randomly selected from the pool. Respondents were then contacted by telephone by the graduate student conducting the interview.

The respondents selected a class period for their interview to take place at a scheduled room at their school. Arrangements were made with teachers to be sure that the time met with their approval. The interviewer met the student at the interview room and then conducted the audio tape-recorded interview. At the 
beginning of the interview, the respondent was again informed of the general purpose of the study, the confidentiality of his/her responses, and the right to withdraw at any time. In addition to the theoretically guided questions, subjects were asked standard demographic question, e.g., parents' employment and number of family members. Inquiry into parental employment was used to ascertain socioeconomic status. At the end of the interview, the respondent was thanked for his/her time and reminded that he/she could contact the research team about any subsequent concerns related to the study. The interviews ranged from 35 minutes to 75 minutes $(\underline{m}=50)$.

Audio tapes of the interviews were assigned a number and were kept in a locked cabinet to which only the research team had access. The tapes were then transcribed by a professional transcriber for subsequent analysis.

\section{Analysis}

The research team composed a coding scheme based on content analysis of approximately half of the transcribed data and identification of dominant themes related to the research interests (See Appendix $\mathrm{C}$ for the complete code book). All codes were empirically derived. Trained raters were used to categorize responses based on the coding scheme. The training of raters was provided by Dr. Janice Haaken of Portland State University and included instruction on the definition of themes and supervised practice of theme recognition using actual transcripts. Interrater reliability was assessed by computing Cohen's kappa (Cohen, 1960) for each theme within each data set. Three sets of transcripts were randomly selected to compute kappas. The reliabilities ranged from .57 to $.91(\underline{m}=.66)$. 


\section{RESULTS}

A coding scheme was used to identify themes in the interview material. All of the interviews were coded using the available codes. Only codes that reached a reliability of 60 percent agreement are included in this analysis. Three first order categories of codes (i.e., Helping Behavior, Problems Associated with Drug Use, and Treatment of Users and Dealers) with the highest reliability were the focus of subsequent analysis. Each category was associated with a particular section of the interview. Of the 26 tests of significance conducted on the variables, 2 were significant for grade, 2 were significant for gender, and 1 was significant for race (See Table 2 for a summary of significant and marginally significant findings).

Table 2: Significant and Marginally Significant Findings

$\begin{array}{lll}\text { Code } & \text { Frequency } & \chi^{2}\end{array}$

$\begin{array}{lll}\text { HELP-NO } & 4 \text { th }=3 & \chi^{2}=4.48, \\ \text { Eleventh grade } & 11 \text { th }=11 & p<.05\end{array}$

students were

more likely to

specifically

reject some

category of help)

TEACH

(Fourth grade

students were

more likely to

consider teachers

as a source of help)
$4 \mathrm{th}=10$
$\chi^{2}=3.48$
11 th $=3$
$p<.06$ 


\begin{tabular}{|c|c|c|}
\hline $\begin{array}{l}\text { RISK-SELF } \\
\text { (Female students } \\
\text { were more likely } \\
\text { to acknowledge risk } \\
\text { to self due to } \\
\text { helping.) }\end{array}$ & $\begin{array}{l}\text { Female }=28 \\
\text { Male }=21\end{array}$ & $\begin{aligned} \chi^{2} & =4.27 \\
p & <.06\end{aligned}$ \\
\hline $\begin{array}{l}\text { RISK-FREND } \\
\text { (Caucasian } \\
\text { students were } \\
\text { more likely to } \\
\text { acknowledge that } \\
\text { there may be risks } \\
\text { to the helpee due } \\
\text { to helping) }\end{array}$ & $\begin{array}{l}\text { Caucasian }=10, \\
\text { African } A m=4\end{array}$ & $\begin{array}{l}\chi^{2}=3.52 \\
p<.06\end{array}$ \\
\hline $\begin{array}{l}\text { DEALER-PUNISH } \\
\text { (Male students } \\
\text { were more likely } \\
\text { to want punishment } \\
\text { and control of } \\
\text { drug dealers) }\end{array}$ & $\begin{array}{l}\text { Female }=1 \\
\text { Male }=8\end{array}$ & $\begin{array}{l}\chi^{2}=5.32 \\
p<.05\end{array}$ \\
\hline
\end{tabular}

The first code set is of Helping Behavior (See Appendix D for a summary of code definitions). Initially, subjects were presented with a dilemma in which a hypothetical friend must decide whether or not to help a peer who is having a drug problem. When faced with this dilemma, 100 percent $(n=64)$ of the subjects indicated a general orientation or readiness to give the friend help (HELP-YES) (See Appendix E-1 for a summary table of Helping Behavior data). This response included a general response to helping before the type of helping was probed. Approximately 22 percent of the subjects did reject some form or method of helping (HELP-NO). Of the 14 subjects who mentioned HELP-NO, 3 (21\%) were 4th graders, $11(78 \%)$ were 11 th graders, $10(71 \%)$ were Caucasian, $4(28 \%)$ were 
African American, $8(57 \%)$ were male, and $6(42 \%)$ were female. The difference between 4 th graders and 11 th graders was significant at $\chi^{2}=4.48, p<.05$ (Yates corrected), $d f=1$

Second-order codes established the direction and form of help. Transcripts were assigned codes to indicate whether subjects would endorse help through individual information seeking (HELP-IND-INFO), help through individual action (HELP-IND-ACT), or help through involving or enlisting others to directly intervene (HELP-SOC-ACT). Only $6(9 \%)$ of the subjects mentioned themes that were coded with HELP-IND-INFO. Gender, race, and grade were not significant variables. Twenty-three subjects (36\%) mentioned statements that were coded as HELP-IND-ACT. Of those 23 subjects, six (26\%) were 4th graders and $17(74 \%)$ were 11 th graders. HELP-SOC-ACT was used most frequently. Fifty-nine (92\%) of the subjects mentioned the theme of HELP-SOC-ACT. The theme was used evenly between the two grades, and between gender and race.

Transcripts were coded to identify subjects who endorsed intervention and to record what contingencies, if any, they would place on such interventions. Subjects were more apt to identify family as a source of help than any other category of help givers. Fifty-seven (89\%) transcripts identified family as a source of help (FAMHELP). Significant differences were not found between gender, race, and grade groups. FAM-ONLY-HELP was given for subjects who mentioned that a family member should be the only source of help. Only one transcript was given this code. FAM-MAY-C was given to transcripts which acknowledged that family is the only source of help if the family can be caring and understanding. Twelve (19\%) of the subjects were given the FAM-MAY-C code. Again, significant differences were not found between gender, race, and grade groups. 
The next category of helpers were experts. EXPERT-HELP was the code that represents general statements that experts are a source of help. Forty (63\%) of the subjects responded with such general responses. EXPERT-ONLY-HELP characterized statements that suggested that adult intervention or help must be based on knowledge of drugs or counseling skills exclusively. No subject mentioned this theme. Two related codes which attempted to make further distinctions and contingencies for experts as helpers were not used. They are EXP-MAY and EXPMAY-P. EXP-MAY represents statements that experts may be a source of help without specifying qualities or skills that enable experts to be helpful. EXP-MAY-P refers to statements that experts are helpful if they have the authority or power to monitor behavior. Several subjects (5\%) expressed that experts are helpful if based on a caring or genuine interest in the welfare of the helpee (EXP-MAY-C).

The last categories of helpers were teachers and administrators. Thirteen (20\%) of the subjects stated that teachers are a source of help (TEACH). Significant differences were not found between Caucasian and African American subjects and between males and females. Some difference was found between 4 th $(77 \%)$ and 11 th $(23 \%)$ graders, $\chi^{2}=3.48, p<.06$ (Yates corrected), $d f=1$. The code TEACH-MAY captured responses that indicated that teachers may be or are sometimes a source of help. No subjects were given this code. TEACH-MAY-C, a theme reflecting statements that teachers are helpful if based on a caring relationship or genuine interest in the welfare of the student, was mentioned by only one student. ADMNN, administrators such as principals and vice-principals are a source of help, was also mentioned by only one subject. No subjects made the distinction that administrators may be or are a potential source of help (ADMIN-MAY).

Another category of helping behavior involves the extent to which helping is 
contingent upon the magnitude of risk. RISK is the code given to any mention of risk involved in saying or doing something about the problem that does not specifically mention the type of risk. Eighteen (28\%) of the subjects mentioned this code. No real differences were found between the various groups of subjects. RISK-SELF is the code given for subjects who recognize that when action is taken, there may be negative consequences to the person who took action. Forty-nine (77\%) subjects gave this response. A significant difference between males ( $43 \%)$ and females (57\%) was found on RISK-SELF, $\chi^{2}=4.27, p<.04, d f=1$. RISKFRIEND was given to subjects who recognize that when action is taken, there may be negative consequences to the friend. Fourteen subjects (22\%) mentioned this theme. Some difference was found between Caucasian (71\%) and African American (29\%) subjects, $\chi^{2}=3.52, p<.06$ (Yates corrected), $d f=1$. Caucasian students were more likely to mention negative consequences to the friend. The response that action is warranted if people other than the user are at risk of being hurt (RISKOTHR) was made by only one subject.

The last category of helping involves positive outcomes of helpful actions. HELP-SELF characterized subjects who stated that helping is important because there are personal benefits from telling, such as relieving tension or receiving gratitude. Thirty-three subjects (52\%) mentioned some personal benefit. No differences between groups were found. HELP-OTHR was given to subjects who believed that intervening provides a lesson to others about consequences of drug use. Two subjects mentioned this theme. Both subjects were Caucasian males.

The second code set consisted of problems associated with drug use (See Appendix E-2 for a summary table of data regarding Problems Associated with Use). Codes were assigned to statements made in response to the question "How 
much do people have to use to have a drug problem?" The question captured themes about how drug use is problematic and to whom it is problematic. The first code states that a problem emerges when there is a potential for physical harm to the self (HARM-PHY-SELF). Twenty-nine (45\%) of the subjects mentioned this theme. No significant differences were found between the two grades, genders, or classes on this code. The next code states the physical harm to others is seen as problematic (HARM-PHYS-OTHER). Only five ( $8 \%$ ) of the transcripts identified this theme. The next subset of the problem codes involves emotional consequences of drug use. Statements that a problem emerges when there is a potential for emotional damage to the self due to drug use was coded as HARM-EMOT-SELF. This theme was mentioned in $20(31 \%)$ of the transcripts. Statements that a problem emerges when there is emotional damage done to others due to drug use were coded as HELP-SELF. This theme was mentioned in five ( $8 \%)$ of the transcripts.

The next group of codes were given in response to the question "How much do you have to use drugs to have a problem?" A statement that any and all use of illegal drugs is a problem was assigned DRUG-PATH (Drugs Pathological). The code includes the idea of "instant addiction" or lethal effects of any experimentation. DRUG-PATH was mentioned in $42(66 \%)$ of the transcripts. Any statement that drug use becomes a problem only after a particular frequency or time period of use was assigned the code of DRUG-FREQ Drugs Pathological if Frequent). Thirtyfive (55\%) transcripts contained this theme. The last code assigned to responses to the drug problem question is DRUG-RAT (Pathology Contingent on Rationale). DRUG-RAT states that drug use is a problem if it becomes a means of solving problems or dealing with difficulties in living. This theme was mentioned by only 
three $(5 \%)$ of the respondents.

\section{Treatment of Users and Dealers}

The third code set involved respondents' perceptions about how drug users and dealers should be treated (See Appendix E-3 for a summary table of Treatment of Users' data). The treatment of users will be discussed first. The first code characterized statements that treatment of users should be based on general respect and that users should have the same rights as others (U-TREAT-RESPECT). Thirty-three (51\%) transcripts included this theme. The next code states that treatment of users should be based upon therapeutic aid (U-TREAT-THER). It was mentioned in nineteen $(25 \%)$ of the respondents. The provision of treatment-based hospital or medical aid to use was given the code U-TREAT-MED. Eight (13\%) transcripts were assigned this code. Statements that treatment should be based on a combination of therapeutic and medical aid were coded as U-TREAT-COMB. This code was evident in seven $(11 \%)$ of the transcripts. All of the respondents who mentioned this code were 11 th graders. Statements that user intervention should involve punishment or social control without treatment were given the code $\mathrm{U}$ PUNISH. Nine (14\%) of the transcripts referred to this theme. Respondents who mentioned that punishment should be combined with education or counseling were coded as U-PUNISH-THER. This theme was found in only one transcript. The last user treatment code involves the idea that users should be physically removed or isolated from others or society to gain control over their behavior (U-TIME). This code was mentioned in eight $(13 \%)$ of the transcripts.

The following codes involve interventions with drug dealers. Statements that dealers deserve to be treated with respect and have the same rights as others were coded as D-TREAT-RESPECT. Six (9\%) transcripts were scored on this code. 
Statements that intervention with drug dealers should be based on non-punitive, respectful treatment or providing aid based on expertise or cousneling skills were coded as D-TREAT-THER. Five (8\%) of the transcripts included this theme. DPUNISH was assigned to statements that drug dealer intervention should include punishment or social control of dealers, such as jail time. Thirty-nine (61\%) transcripts showed the code D-PUNISH. Of the 39 subjects who used D-PUNISH, $24(61 \%)$ were males and $15(38 \%)$ were females. This difference was significant, $\chi^{2}=5.32, p<.05, d f=1$. 


\section{DISCUSSION}

This study explored the perceptions of 64 fourth-grade and eleventh-grade students about helping responses to peers involved with drug use. In addition, perceptions of problems associated with drug use, and interventions associated with using and dealing, are explored. The following discussion focuses on themes which both satisfied the reliability criterion of .60 and were found to show a significant association with age, gender and race. Six significant findings will be discussed; in addition, marginally significant associations, which are often examined in exploratory studies, will also be discussed. General patterns and findings of association will also be discussed and examples from the interviews will be presented to place quantitative findings in the context of respondents' own narrative accounts.

\section{Helping Behavior}

When asked if a friend should help another friend who is using drugs, respondents provided a range of helping responses. All of the respondents indicated that some form of helping is necessary. Despite a readiness to help by all, a few respondents specifically rejected some form of helping (HELP-NO). A significant difference was found between fourth and eleventh grade responses of HELP-NO, with the eleventh grade students using HELP-NO more often. The older students may have been more able to perceive the complexities and costs of helping and therefore were more reluctant to help. They could perceive that some forms of helping may cause more problems for the helpee. Keller and Edelstein (1991) argue that socio-moral decision making is related to the development of the ability to 
understanding persons, relations, and actions. As children develop, they become increasingly able to consider the complexities of their actions and their effects on others. Also, older students are presumably closer to drug issues and are more likely to experience the kinds of scenarios presented in the study. Carpenter, Glassner, Johnson, and Loughlin (1988) argue that youth who are less involved with drug issues give responses to drug-related questions which are more brief and lacking in complexity. Perhaps the inexperience of the younger participants with drug situations contributed to their lessened tendency to mention the costs of helping.

Another significant finding between younger and older participants was in the tendency to mention themes that are characteristic of the code TEACH. TEACH was used to capture statements that teachers could be a source of help to students. Younger students were apparently more willing to trust teachers for help with a drug situation.

An example of a 4th grade response to the question of who should be told is "[tell] a teacher who is close to her or him."(S\#3,C,F) The following is an 11th grade response to the same question:

I'd say it depends on what grownup. I mean, if you are telling, like, a teacher or something, that could, like, get them into trouble. I'd say it's wrong. But if you are telling, like, a good friend that's an adult or parent, then I'd say there wasn't any problem.(S\#39,C,M)

Again, the 11th graders may have been more likely to perceive the complexities of helping and therefore were not willing to take the risk of involving teachers (Keller $\&$ Edelstein, 1991). Potential risks may include non-compassionate reactions from teachers, teachers not respecting confidentiality, and teachers not grading the 
student fairly. Another explanation may be that adolescents may be more likely to sense the control function that teachers represent. Adolescents may know that teachers are authority figures who may feel obligated to report drug use. Young children may not be aware that teachers have such obligations until they are older.

Since the design of the present study is cross-sectional, it is neccessary to present some alternative explanations for age differences. The children and adolescents who participated in this study grew up during different historical eras with differing contexts of drug education. Therefore, the differences just discussed as age differences may in reality be cohort differences. Oregon now has a comprehensive drug education program for students from Kindergarten to grade twelve (Mielke \& Holstedt, 1992). Younger generations of all ages are now receiving specific information and participating in exercises that increase their awareness about drugs and drug dilemmas. In fourth and fifth grades, for example, students are specifically asked to name people and discuss some people whom they trust and with whom they could discuss their drug problems (Mielke \& Holstedt, 1992). Teachers are suggested as a source of trust and help by the curriculum. The changes in the media may also create differences in drug perception environments between cohorts.

Another category of helping behavior is the set of risk codes. The set involves the extent to which helping is contingent upon the magnitude of risk. It is interesting to note that no grade differences were found in the use of the risk codes. A significant difference was found between males and females in the use of RISKSELF. Females were more likely to recognize that when action is taken there may be negative consequences to the person who took action. Negative consequences may include loss of friends, loss of reputation, or exposure to personal problems with drugs. One possible explanation of this finding is that girls are more likely to 
avoid struggle. Hunt (1990) argues that when girls are faced with a problem, they tend to choose solutions which lead to minimal conflict for everyone. The drug situations often pose a dilemma between offering help and creating other problems. The other problems may not be worth the struggle to some girls. They may not feel as though they have the confidence to deal with the other problems. An example of a female response is

I think [the friend] would really be mad at her for telling because she's addicted to crack now, probably. I think she would be mad at her, at first, for telling until she probably got over it, through it.(S\#43)

Another example of a female response is "[the friend] might feel bad and the [helper] might feel sort of bad and good, because she did the right thing of telling. And she also had kept a promise" (S\#4). Hunt (1990) argues that males tend to help more in risky situations and females tend to help more in situations requiring comforting or healing. Since the dilemmas presented in the study pose an opportunity to comfort and support with some risks, the females were willing to help but also acknowledged the potential for risk. Indeed, females were as willing to help as males despite their acknowledgment of risks to themselves.

Another difference in responses involving risk was found between AfricanAmerican and Caucasian participants on the use of RISK-FRIEND. Caucasian students were more likely to recognize that when action is taken, there may be negative consequences to the helpee. Possible negative consequences include punishment, notification of parents, unfair treatment by parents, and emotional difficulties for the student. This finding is difficult to explain since it was expected that African-American students would be more likely to see and feel the negative consequences of drug use and abuse in their community. Possible negative 
consequences are often unfairly harsh for African-Americans because of discriminatory policies. This area of assessing risk may have a complex cultural dimension that requires further inquiry.

\section{Treatment of Users and Dealers}

The last significant difference involved respondents' perceptions of appropriate treatment of drug dealers. Males were more likely to endorse punishment of drug dealers than females. The idea of punishment of dealers involves social control of dealers. Respondents endorsed the belief that dealers should be put in jail without psychological treatment. An example of a 4th-grade, male respondent's reaction to the treatment of drug dealers is that they "should just be put in jail forever, not let them be out"(S\#2). An example of a 4th grade female response is:

you could, like, talk to them about how drugs can affect your life and how they can really mess up your brain, you know. 'Cause they're so bad for your body. And, you know, they could probably listen if you can get into a person. (S\#4)

Brody (1984) presents evidence that elementary school girls are more likely than boys to experience sadness and boys are more likely to experience anger in hypothetical situations that elicit emotion. It is possible that the males' initial reaction to someone who commits a crime is anger and the females' response is sadness and compassion for the person.

\section{Limitations}

Interpretation of these data should consider limitations of the data and the datacollection process. All of the participants were volunteers from area classrooms. Despite efforts by the researchers to seem non-judgmental and attempts to elicit a broad sample, volunteers may have characteristics that do not represent all school 
children and adolescents. For example, students who are more comfortable with adults may be more represented in this sample.

Characteristics of the interviewers are another possible limitation. Three interviewers were used in order to prevent possible biases of the researchers. Each interviewer received a random representation of students from each grade, gender, and race to interview. Interviewing styles inevitably varied somewhat despite the structure of the interview and careful training of the interviewers. The three interviewers were Caucasian students from similar backgrounds. Ideally, the interviewers should represent the races of the subjects involved. Possible differences between interviewer styles and backgrounds may have influenced subjects' willingness to share information.

Future Research

Suggestions for future research include replication of the study with other age groups. Comparison of two particular age groups is not sufficient to explain all developmental differences in children's perceptions of drug use. Future research may also consider the use of a self-report questionnaire based on the open-ended interview and the range of responses given in this study. The use of codes to represent children's statements has potential for error and misrepresentation. Data

collected from interviews and questionnaires together can provide more information about possible developmental, gender, and racial differences. Also, sequential designs are necessary to ascertain the extent of cohort effects.

\section{Conclusions}

In general, the findings indicate that there are fewer developmental, gender, and race differences in children's conceptions of drug use and associated dilemmas than might be expected. It is important that drug education programs present 
information with developmentally appropriate techniques. Apparently, however, children's conceptions of some drug issues do not vary significantly between fourth and eleventh grade. Children of different ages are perceiving similar risks about drug use and have similar attitudes toward helping dilemmas. Similarly, gender and racial differences in attitudes are not well supported by the present study.

Since the findings of the present study did not reveal significant developmental, gender or race differences, other aspects of participants' thinking can provide insights about drug education. Participants' descriptions of drug issues generally revealed that students are thinking and reasoning about the information that is being given. Since the information provided in drug education programs is not always effective in changing attitudes or drug-using behavior, it may be necessary to examine the extent of information given and the techniques used to present it (Moskowitz, 1989). Participants' statements also revealed some confusion and some contradiction in thinking. Again, the information is presented, but it may not provide answers to confusions that students face during their lives. Students see contradiction in messages that they receive from school, family, friends, media and society in general. Possible techniques for education programs may include open discussion of those contradictions and presentation of all aspects of drug use. 


\section{REFERENCES}

Baumrind, D. (1978). A dialectical materialist's perspective on knowing social reality. In W. Damon (ed.) New directions for child development: No. 2 Moral development, $61-82$.

Blasi, A. (1980). Bridging moral cognition and moral action: A critical review of the literature. Psychological Bulletin, $\underline{88}, 1$ - 45.

Blasi, A. (1983). Moral cognition and moral action: A theoretical perspective. Developmental Review, $\underline{3}, 178-210$.

Boldizar, J. P., Wilson, K. L. \& Deemer, D. K. (1989). Gender life experiences and moral judgment development: A process-oriented approach. Journal of Personality and Social Psychology, 57, 229-238.

Braught, G. \& Braught, B. (1984). Prevention of problem drinking among youth: Evaluation of educational strategies. In P. Miller \& T. Tiremberg (eds.), Prevention of alcohol and abuse. New York: Plenum Press, 253-279.

Brody, L. R. (1984). Sex and age variations in the quality and intensity of children's emotional attributions to hypothetical situations. Sex Roles, 11, 51-59.

Brownfield, D. (1986). Social class and violent behavior. Criminology, 24(3), $421-438$

Burton, R. V. (1984). A paradox in theories and research in moral development. In W. M. Kurtines \& J. L. Gewirtz (Eds.), Morality, moral behavior, and moral development. New York: Wiley.

Carpenter, L, Glassner, B., Johnson, D. J. \& Loughlin, J. (1988). Kids, Drugs, and Crime. Toronto: Lexington Books.

Cohen, J. (1960). A coefficient of agreement for nominal scales. Educational and Psychological Measurement, 20, 7 - 20. 
Dixon, K. (1984). The coercion of labor by mental health professionals. Social Policy, 14(4), 47-54.

Ford, M. R. \& Lowery, C. R. (1986). Gender differences in moral reasoning: A comparison of the use of justice and care orientations. Journal of Personality and Social Psychology, 50, 777-783.

Gilligan, C. (1982). In a different voice. Cambridge: Harvard Press.

Gilligan, C \& Attanucci, J. S. (1988). Two moral orientations: Gender differences and similarities. Merrill-Palmer Quarterly, 34, 223 - 237.

Gilligan, C. \& Belenky, M. (1980). A naturalistic study of abortion decisions. In. R. Seligman \& R. Yando (eds.) New directions for clinical developmental psychology. San Francisco: Jossey-Bass.

Glassner, B. \& Loughlin, J. (1987). Drugs in adolescent worlds. Macmillan Press Ltd.: Houndmills, 245.

Goodstadt, M. \& Sheppard, M. (1983). Three approaches to alcohol education. Journal of Drug Education, 10(2), 89-99.

Hansen, W. B, Johnson, C. A., Flay, B. R., Graham, J. W., and Sobel, J. (1988). Affective and social influence approaches to the prevention of multiple substance abuse among seventh grade students: Results from project SMART, Preventive Medicine, $\underline{17}, 11-20$.

Harding, S. (1987). The curious coincidence of feminine and African moralities: challenges for feminist theory. In E. F. Kittay \& D. T. Meyers (eds.), Women and moral theory, 296-315. Totowa, N.J.: Rowman and Littlefield.

Hunt, M. (1990). The compassionate beast. New York: William Morrow. Jessor, R., Chase, J. A. \& Donovan, J. E. (1980). Psychosocial correlates of marijuana use and problem drinking in a national sample of adolescents. American 
Journal of Public Health, 70, 604-613.

Johnston, K., Brown, L., \& Christopherson, S. (1990). Adolescents' moral dilemmas: The context. Journal of Adolescence, 19,615 - 622 .

Keller, M \& Edelstein, W. (1991). The development of socio-moral meaning making: Domains, categories, and perspective-taking. In W. M. Kurtines \& J. L Gewirtz (eds.) Handbook of moral behavior and development, Volume 2: Research. Hillsdale, N.J.: Lawrence Erlbaum, 89-114.

Kohlberg, L. (1963). Moral development and identification. In H. W. Stevensen. (eds.), Child Psychology: 62nd yearbook of the national society for the study of education. Chicago: University of Chicago Press.

Kohlberg, L. (1969). Stages in the development of moral thought and action. New York: Holt.

Langsdale, C. J. (1986). A re-vision of the structural-developmental theory. In G. L. Sapp (ed.) Handbook of moral development: Models, processes, techniques, and research, 15-54.

Leming, J. S. (1978). Cheating behavior: Situational influence and moral development. Journal of Education Research, 71, 214-217.

Lyons, N. P. (1983). Two perspectives on self, relationships, and morality. Harvard Educational Review, $\underline{53}, 125-145$.

Mauss, A., Hopkins, R. Weisheit, R. \& Kearney, K. (1988). The problematic prospects for the prevention in the classroom: Should alcohol education programs be expected to reduce drinking in youth? Journal of Studies on Alcohol, 49, 51-61.

Mielke, D. \& Holstedt, P. (1992). Oregon Alcohol and Drug Prevention Education (ADAPE): Infused Lesson Guide, K-12. Salem: Oregon Department of Education Publications. 
Mohr, P. H., Sprinthall, E. R. \& Gerler, J. R. (1987). Moral reasoning in early adolescence: Implications for drug abuse prevention. The School Counselor, 11, 120-127.

Moskowitz, J. M. (1989). The primary prevention of alcohol problems: A critical review of the research literature. Journal of Studies of Alcohol, $\underline{50}, 54-88$.

Moskowitz, J. M., Schaps, G., Schaffer, \& Marvin, J. (1986). Evaluation of a substance abuse prevention program for Junior High School students. International Journal of the Addictions, 21, 1081-1112.

Newcomb, M. d. \& Bentler, P. M. (1985) Substance use and ethnicity: Differential input of peer and adult models. Journal of Psychology, 120, 83-95

Oetting, E. R. \& Beauvais, F. (1987). Common elements in youth drug abuse: Peer clusters and other psychosocial factors. Joumal of Drug Issues, $\underline{17}, 133-151$.

Pascale, P. J., Trucks, S. F. \& Sylvester, J. (1985). Regional trends and sex differences of drug use and attitudes of High School students in Northeast Ohio, 1977-1983. Journal of Drug Education, 15(3), 241-251.

Pentz, M. A., Dwyer, J. H., Mackinnon, D. P. Flay, B. R., Hansen, W.B., Wang, E. Y., and Johnson, C. A. (1989). A multi community trial for primary prevention of adolescent drug abuse, Journal of the American Medical Association, 261, 3259 3266.

Shweder, R. A., Mahapatra, M. \& Miller, J. (1987). Culture and moral development. In J. Kagan \& S. Lamb (Eds.) The Emergence of Morality in Young Children, University of Chicago Press: Chicago.

Tobler, N. S. (1986). Meta-analysis of 143 adolescent drug prevention programs: Quantitative outcome results of program participants compared to a control or comparison group. Journal of Drug Issues, $\underline{16}, 537-567$. 
Thompson, E. L. (1978). Smoking education programs. American Journal of Public Health, $\underline{68}, 250-257$.

Tucker, D. O. \& Locke, D. C. (1986). The manipulation of race in moral dilemmas: Implications for moral education and human relations. Educational and Psychological Research, $\underline{6}$, 99-109.

Walker, L. J. (1984). Sex differences in the development of moral reasoning: A critical review, Child Development, 55, 677-691.

Walker, L. J. (1986). Sex differences in the development of moral reasoning: A rejoinder to Baumrind. Child Development, $\underline{57}, 522-526$.

Walker, L. J., DeVries, B. Trevethan, S. D. (1987). Moral stages and moral orientations in real-life hypothetical dilemmas. Child Development, $\underline{58}, 842-858$.

Walker, L. J. (1989). A longitudinal study of moral reasoning. Child Development, $60,17-16$ 
APPENDIX A

\section{CONSENT FORM}

I, hereby agree to serve as a subject in the research project entitled "Youth, Drugs and Society" under the supervision of Dr. Janice Haaken.

I understand that the study generally involves participation in a fifty minute audio tape recorded interview which will take place during one class time at a private room in my school.

I understand that generally interviews of this kind can be a positive experience, although some people may experience feelings of discomfort about discussing their thoughts or feel inconvenienced by missing class time.

It has been explained to me that the purpose of the study is to learn how young people understand and think about problems of drug use and drug abuse. I also understand that the interview will not include questions about my own personal experiences of use nor of people that I know. I may not receive any direct benefit from this study, but my participation may help increase knowledge which may benefit others in the future.

Dr. Janice Haaken has offered to answer any questions or concerns that I may have about the study, either before or after my participation. I have been assured that all information that I give will be kept confidential and neither my name nor identity will be used for any written paper or public discussion that result from this study.

Date Student Signature

Date Parent Signature

If you experience problems that are the result of your participation in this study, please contact the Chair of Human Subjects Review Committee, Office of Grants and Contracts, 303 Cramer Hall, Portland State University, 725-3417. 


\section{APPENDIX B \\ INTERVIEW SCHEDULE}

\section{$\underline{\text { Vignettes }}$}

\section{A. Vignette \#1}

John (Susan) is a sixteen year old boy (girl) who knows that his (her) best friend Bill (Amy) smokes crack allot. John (Susan) doesn't know much about the drug but he (she) knows that Bill (Amy) is getting skinnier, skipping school more, and pulling away from his (her) other friends. Bill (Amy) has begged John (Susan) not to tell anyone and told him (her) that he (she) would not be his (her) friend anymore if he (she) did. John (Susan) promised not to tell because he (she) knows that they are best friends. John (Susan) still thinks he (she) should do something.

Should John (Susan) do anything or say anything? If so, what?

Is it wrong or right to tell a grown-up when a friend tells you not to?

Is it your duty to do something when you think the friend is hurting themselves?

\section{B. Vignette \#2}

Vicki (Steve) is a 19 year old college student who is good friends with a group of girl (boys) at school. Vicki (Steve) wants to try marijuana but the other girls (boys) don't want her (him) to. The girls (boys) say they won't be her (his) friend anymore if she (he) smokes it because they don't like people who use illegal drugs, even marijuana. Vicki (Steve) also knows that her (his) parents would be upset. Trying the marijuana is very important to Vicki (Steve) so she (he) has read information about marijuana and learned that there is very little chance of becoming addicted and its ii safer than alcohol.

Should Vicki (Steve) smoke the marijuana?

Does she (he) have the right to do it? Why? 


\section{Exploratory Questions}

1) Why do you think people take drugs?

2) What is 'drug abuse'? How much to people have to use to have drug problem?

3) Are there any good reasons to take drugs?

4) Is it wrong to use drugs? Why?

5) Why do you think certain kinds of drugs are against the law? Would you change any thing about the current drug laws?

6) Do you think that any of the drugs that are illegal now should be made legal?

7) Do you think it is ever alright to experiment with a drug that is not prescribed for some specific problem?

8) How do you feel about the way drug users are treated? How do you think drug users should be treated?

9) How do you feel about the way drug dealers are treated. How do you think drug users should be treated?

10) How do you feel about the way the police treat people who have a drug problem? How do you think they should treat be treated? 
APPENDIX C

CODE BOOK

\section{HELPING}

I. Help indicated ( HELP- YES, HELP- NO )

Code HELP-No whenever a relation or category of help is specifically rejected.

(Code HELP- NO if any group of people is rejected.)

* I wouldn't go to school for help because it is really not the school's business.

* I would try to get some help.

* Yes, I think I should say something.

\section{Help-Individual}

Help through individual information seeking (HELP- IND-INFO) (action involves gathering outside information for individual action ) Read about drug use/abuse; Get direct information from abusing friend; Talk to someone with expertise. If source of information is specified, also code from section IV.

* I'd go to my parents and pose a hypothetical problem situation to get their ideas about how to handle it. (also code FAM-HELP, RISK).

Help through individual action (HELP-IND-ACT) taking action which confronts abusing friend on a one-to-one, individual level. Confront the individual with concern about seriousness of problem and importance of getting help; Confront the individual with demand that he/she must stop. Stopping is contingency of friendship; Express concern and offer support or guidance; Stay physically close to friend, as if a close proximity will deter friend from using drugs; Detach - withdraw friendship. (Any mention of getting personally involved in the problem)

* I'd probably push him to quit or to get some kind of help. (45). (HELP-INDACT) (HELP-SOC- ACT) 
III. Help - Social

Help through involving or enlisting others to directly intervene (HELPSOC-ACT) motive for involving outsider is to open the path for outsider to directly intervene. General response that outside intervention is necessary. If helper is specified also code from section IV. (any telling)

* I think she should tell her parents because they could get her to stop. (Also code FAM-HELP)

* Somebody else should tell, just not me. His parents can help by taking him to a treatment center. (Also code FAM-HELP, EXPERT-HELP)

* it don't matter, I would tell somebody

IV. Help contingent on relationships Whether to provide help depends on qualities of help givers or nature of relationships that provide aid.

A. Family helps / Family may help

Only Family Helps ( FAM- ONLY- HELP)

Must be a family member. Only a family member can relate to friend and provide adequate care.

* She should tell her mom and dad, nobody else.

* I believe in keeping it in the family.

Family helps ( FAM- HELP) General response that family is a source of help. Includes reference to parents or any family member.

* I think she should tell her parents.

Family helps if provides caring and understanding (FAM - MAY-C) Family helps if they are perceived to be understanding and/or non-punitive.

B. Adult expertise help / may help

Only experts help (EXPERT-ONLY-HELP) Adult intervention or help must be based on knowledge of drugs or counseling skills. 
Experts help (EXPERT-HELP) General statement that experts are a source of help.

* She should tell a counselor or somebody.

* a rehab center will stop them

Experts may help (EXP-MAY) General focus on capacity of experts to help without specifying qualities of skills that enable experts to be helpful.

Includes references to situations where experts may not help, but recognition that they sometimes can. (Ambivalent re: ability to help)

* I wouldn't go to school for help because it's really not the school's business (45).

Expertise based on caring may help (EXP-MAY-C) Experts are helpful if based on a caring relationship or genuine interest in welfare of helpee.

* rehab people try to be friendly

Expertise based on power (EXP -MAY-P) Experts are helpful if have they the authority or power to enforce or monitor behavior.

C. Teachers help/may help

Teachers help $(\mathrm{TEACH})$ Teachers are a source of help.

* I think she should tell a teacher because they can call her parents and let them know what their daughter is doing. 
Teachers may help (TEACH-MAY) Teachers may be or are sometimes a source of help.

Teachers may help if they are caring people (TEACH-MAY-C) Teachers are helpful if based on a caring relationship or genuine interest in welfare of student.

D. Administrators help/may help

Administrators help (ADMIN) Administrators e.g., principals, viceprincipals, are a source of help.

Administrators may help (ADMIN-MAY) Administrators may be or are a potential source of help.

V. Helpful action contingent on magnitude of risks. (RISK) Action is contingent upon the severity of the risk. Action is defined as doing or saying something about the problem. (Code RISK if nature of risk not specified).

* it would depend upon how bad the problem is.

Action contingent on risk to friend (RISK-FREND) Recognize that when action is taken, there may be negative consequences to the friend. Action is not warranted because of the risk.

Action contingent on risk to self (RISK-SELF) Recognize that when action is taken, there may be negative consequences to the person who took action. Risk can include perceived risk of loss and reputation, friends, or exposure to one's own problems with drugs. (Opposite of HELP-SELF)

* I'd want to protect my reputation more than my friends on drugs. 
* She should not tell anyone or else she will lose her friend.

* I wouldn't want him to know I told because he wouldn't be my friend if he knew.

VI. Positive outcome of helpful actions

Action helpful to self (HELP-SELF) Intervening or helping is important because it relieves tension or stress, permits feeling good about one's self or leads to feelings of gratitude, in the short or long run. (Benefit from telling or action.) (Also see RISK-SELF)

* I think that the reason that I would tell on him is because I want him to still be my friend.

* He'll thank me for it later.

Action helpful to others (HELP-OTHR) Intervening provides a lesson to others about consequences of drug use, permits monitoring of public safety concerns raised by friend's drug use.

* Maybe it will show others that it is not good to use drugs

PROBLEMS ASSOCIATED WITH USE

(Vignettes, How much do people have to use to have a drug problem?)

I. Harmful Effects Focus on critique of drug use (why is it wrong to use drugs) and those factors that make drug use problematic (when does drug use become a problem)

Physically harmful to self (HARM-PHY-SELF) Problem emerges when there is a potential for physical harm to self (e.g. brain damage, drug induced sickness).

* Using drugs is wrong because the user might kill himself

Physically harmful to others (HARM-PHYS-OTHER)

Physical harm to others is seen as problematic (e.g., drug user "goes crazy" and physically violates others, others are hurt by drunk driving)

* It's wrong to use drugs because you could probably end up killing someone. 
* That is what they teach, that it is bad for your health and such.

Emotionally harmful to self (HARM-EMOT-SELF) Problem emerges when there is a potential for emotional damage to self (e.g., loss of self esteem, depression, increased difficulty in school, increased difficulty with friends/family relationships, increased financial hardship) (e.g., having to steal to get money)

Emotionally harmful to others (HARM-EMOT-OTHER) Problem emerges when there is emotional damage done to others (e.g., family and friends feel hurt by user's behavior) (lying or hurting others by dishonesty)

* She would probably hurt other people's feelings when she was high.

* It would hurt her parents to see her this way.

* Her parents would become worried about the way that she is acting.

Harmful or general threat to society (HARM-SOCIETY) Global view of threatening effects of drug use in society as a whole. (legal or illegal) Includes focus on an insidious process of addiction that is pervasive in society.

II. Drugs and Pathology

(How much do you have to use to have a problem?)

Any drug use is pathological (DRUG-PATH) Any and all use of illegal drugs is a problem. Includes idea of "instant addiction" or lethal effects of any experimentation. Even a small amount or use of drugs results in a problem. (e.g., twice, a little, a couple) (Excludes several)

* After twenty times it's a problem

* It's a problem after a certain number of years

* It's bad when drugs are used two times a day.

Pathology contingent on rationale (DRUG-RAT) Drug use is a problem if it becomes a means of solving problems or dealing with difficulties in living. 


\section{INTERVENTIONS WITH USERS AND DEALERS}

I. Interventions with users

( How do you think users should be treated?)

Treatment or response based on general respect

(U-TREAT-RESPECT) Users deserve to be treated with respect and/or have the same general rights as other citizens. Code here if focus on respect but specific intervention is not mentioned.

* They should be treated the same as normal people.

* They should be nice to them and tell them that drugs are bad and they shouldn't do them.

* Treat them the way you are supposed to treat everybody.

Treatment based on therapeutic aid (U-TREAT-THER) Intervention should be based on respectful treatment or providing aid based on expertise. Includes idea that user needs counseling for psychological problems.

Treatment based on medical aid (U-TREAT-MED) Intervention should be based on hospital or medical attention, e.g., detox or other purely physical care.

* You should get them into a hospital or a doctor

Treatment based on combination of therapeutic and medical aid (UTREAT-COMB) Intervention should be based on a combination of psychological counseling and medical or physical treatment, e.g., rehab unit if this implies both medical and psychological.

* They should be in special drug treatment and get help to get drugs out of their mind.

Punishment (U-PUNISH) Intervention should mean punishing or social control of users. Users should be put in jail without treatment. 
Punishment should include therapeutic or medical aid (U-PUNISH-THER) Punishment (i.e. jail or arrest) should be combined with education or counseling or other form of therapeutic aid.

* They should have to go to jail and then have a center where they should have to stay, like a jail.

* They should have a little punishment and little help.

Time Out (U-TIME) Intervention understood as taking time out, i.e., being physically removed or isolated from others or society in order to gain greater control over behavior. Includes idea that jail consists of taking time out rather than punishment.

\section{Intervention with dealers}

Treatment or response based on general respect (D- TREAT-RESPECT)

Dealers deserve to be treated with respect and/or have the same general rights as other citizens. Code here if generally respect based but specific intervention is not mentioned.

* They should be nice to them, like users.

Treatment or response based on therapeutic aid (D-TREAT-THER) Intervention should be based on non-punitive, respectful treatment or providing aid based on expertise. Includes idea that dealer needs counseling.

* They should be put in jail because they are the whole drug problem.

Punishment should include therapeutic aid (D-PUNISH-THER) Punishment should be combined with education or counseling or other forms of therapeutic aid.

* Dealers should take a class in jail that teaches them not to sell drugs.

* There should be money making jobs in jails so dealers can send money to their family while in jail. 
Time out (D-TIME) Intervention understood as taking time out, i.e., being physically removed or isolated from others or society in order to gain greater control over behavior. Includes idea that jail consists of taking time out rather than punishment.

* While they are in jail they might think about others then they will stop doing and dealing drugs.

Punishment of dealers (D-PUNISH) Intervention should mean punishing or social control of dealers. Dealers should be put in jail without treatment.

* They should be thrown in jail forever 
APPENDIX D

\section{SUMMARY OF CODES}

\begin{tabular}{|c|c|}
\hline Code & Content \\
\hline$\overline{\text { Help-YeS }}$ & Help is indicated \\
\hline Help-No & A category of help is specifically rejected \\
\hline Help-Ind-I & $\begin{array}{l}\text { Help through individual information } \\
\text { seeking }\end{array}$ \\
\hline Help-Ind-A & Help through individual action \\
\hline Help-Soc-A & $\begin{array}{l}\text { Help through involving others to } \\
\text { directly intervene }\end{array}$ \\
\hline Fam-O-He & Help must be from a family member \\
\hline Fam-Help & $\begin{array}{l}\text { General response that family is a source } \\
\text { or help }\end{array}$ \\
\hline Fam-May-C & Family helps if caring and understanding \\
\hline Exp-O-He & Help must be based on expertise \\
\hline Exp-May-C & $\begin{array}{l}\text { Experts are helpful if based on caring } \\
\text { relationship with helpee }\end{array}$ \\
\hline Exp-My-P & $\begin{array}{l}\text { Experts helpful if based on the authority } \\
\text { or power to enforce }\end{array}$ \\
\hline Teach & Teachers are a source of help \\
\hline Teach-May & $\begin{array}{l}\text { Teachers may be or are sometimes a } \\
\text { source of help }\end{array}$ \\
\hline Teach-M-C & $\begin{array}{l}\text { Teachers are helpful if based on a } \\
\text { caring relationship }\end{array}$ \\
\hline Admin & Administrators are a source of help \\
\hline Ad-May & Administrators may be a source of help \\
\hline Risk & $\begin{array}{l}\text { Action is based on severity of risk. Risk } \\
\text { not specified }\end{array}$ \\
\hline Risk-Fr & Action contingent on risk to friend \\
\hline Risk-Se & Action contingent on risk to self \\
\hline Risk-Oth & Action contingent on risk to others \\
\hline Help-Se & $\begin{array}{l}\text { Action is helpful to self (receives } \\
\text { gratitude, relieves stress) }\end{array}$ \\
\hline Help-Oth & $\begin{array}{l}\text { Action helpful to others (provides } \\
\text { lessons, improves safety) }\end{array}$ \\
\hline Harm-Phy-S & $\begin{array}{l}\text { Drugs are wrong because physically } \\
\text { harmful to self }\end{array}$ \\
\hline Harm-Phy-O & $\begin{array}{l}\text { Drugs are wrong because physically } \\
\text { harmful to others }\end{array}$ \\
\hline
\end{tabular}




\begin{tabular}{|c|c|}
\hline Code & Content \\
\hline 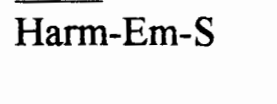 & $\begin{array}{l}\text { Drugs are problematic when emotionally } \\
\text { harmful to self }\end{array}$ \\
\hline Harm-Em-O & $\begin{array}{l}\text { Drugs are problematic when emotionally } \\
\text { harmful to others }\end{array}$ \\
\hline Harm-Soc & $\begin{array}{l}\text { Drugs use is problematic because threat } \\
\text { society as a whole }\end{array}$ \\
\hline Drug-Path & $\begin{array}{l}\text { Any and all drug us is a problem. Small } \\
\text { amount is a problem }\end{array}$ \\
\hline Drug-Freq & $\begin{array}{l}\text { Drugs use is a problem after a specific } \\
\text { quantity is consumed }\end{array}$ \\
\hline Drug-Rat & $\begin{array}{l}\text { Drug use is a problem if used to solve } \\
\text { difficulties in living }\end{array}$ \\
\hline U-Treat-R & $\begin{array}{l}\text { Treatment of users should be based on } \\
\text { general respect }\end{array}$ \\
\hline U-Treat-Th & $\begin{array}{l}\text { Treatment of users should be based on } \\
\text { respectful therapy }\end{array}$ \\
\hline U-Treat-Med & Treatment should be based on medical aid \\
\hline U-Treat-C & $\begin{array}{l}\text { Intervention based on combination of } \\
\text { therapy and medical aid }\end{array}$ \\
\hline U-Punish & $\begin{array}{l}\text { Intervention should mean punishment or } \\
\text { control }\end{array}$ \\
\hline U-Punish-Ther & $\begin{array}{l}\text { Punishment should be combined with } \\
\text { education or counseling }\end{array}$ \\
\hline U-Time & $\begin{array}{l}\text { Intervention should involve being removed } \\
\text { from others }\end{array}$ \\
\hline D-Treat-R & $\begin{array}{l}\text { Dealers deserve to be treated with } \\
\text { respect }\end{array}$ \\
\hline D-Treat-Ther & $\begin{array}{l}\text { Treatment of dealers should be based on } \\
\text { therapeutic aid }\end{array}$ \\
\hline D-Punish & $\begin{array}{l}\text { Intervention should mean punishment of } \\
\text { dealers }\end{array}$ \\
\hline
\end{tabular}


APPENDIX E

SUMMARY TABLES OF DATA 
Table E-1: Frequency of Codes Mentioned Concerning the Helping Behavior for Fourth and Eleventh Grade, Caucasian and African American, and Male and Female Respondents.

\begin{tabular}{|c|c|c|c|c|c|c|c|}
\hline CODE & $\begin{array}{l}\text { Total } \\
n=64\end{array}$ & $\begin{array}{l}4 \text { th } \\
n=32\end{array}$ & $\begin{array}{l}11 \text { th } \\
n=32\end{array}$ & $\begin{array}{l}\text { Cau } \\
n=32\end{array}$ & $\begin{array}{l}\mathrm{AA} \\
\mathrm{n}=32\end{array}$ & $\begin{array}{l}\text { Male } \\
n=32\end{array}$ & $\begin{array}{l}\text { Female } \\
n=32\end{array}$ \\
\hline Help-Yes & 64 & 32 & 32 & 32 & 32 & 32 & 32 \\
\hline Help-No & 14 & 3 & 11 & 10 & 4 & 8 & 6 \\
\hline Help-Ind-I & 6 & 3 & 3 & 3 & 3 & 3 & 3 \\
\hline Help-Soc-A & 59 & 31 & 28 & 32 & 27 & 31 & 28 \\
\hline Fam-O-He & 1 & 0 & 1 & 0 & 1 & 1 & 0 \\
\hline Fam-Help & 57 & 26 & 31 & 25 & 32 & 31 & 26 \\
\hline Fam-May-C & 12 & 5 & 7 & 5 & 7 & 5 & 7 \\
\hline Expert-Help & 40 & 18 & 22 & 21 & 19 & 20 & 20 \\
\hline Exp-O-He & 0 & 0 & 0 & 0 & 0 & 0 & 0 \\
\hline Exp-Мay-C & 3 & 2 & 1 & 3 & 0 & 1 & 2 \\
\hline Exp-May-P & 0 & 0 & 0 & 0 & 0 & 0 & 0 \\
\hline Teach & 13 & 10 & 3 & 6 & 7 & 5 & 7 \\
\hline Teach-May & 0 & 0 & 0 & 0 & 0 & 0 & 0 \\
\hline Teach-M-C & 1 & 1 & 0 & 1 & 0 & 0 & 1 \\
\hline Admin & 1 & 1 & 0 & 1 & 0 & 1 & 0 \\
\hline Ad-May & 0 & 0 & 0 & 0 & 0 & 0 & 0 \\
\hline
\end{tabular}


Table E-1 continued: Frequency of Codes Mentioned Concerning the Helping Behavior for Fourth and Eleventh Grade, Caucasian and African American, and Male and Female Respondents.

\begin{tabular}{llllllll} 
CODE & $\begin{array}{l}\text { Total } \\
\mathrm{n}=64\end{array}$ & $\begin{array}{l}4 \text { th } \\
\mathrm{n}=32\end{array}$ & $\begin{array}{l}11 \text { th } \\
\mathrm{n}=32\end{array}$ & $\begin{array}{l}\text { Cau } \\
\mathrm{n}=32\end{array}$ & $\begin{array}{l}\text { AA } \\
\mathrm{n}=32\end{array}$ & $\begin{array}{l}\text { Male } \\
\mathrm{n}=32\end{array}$ & $\begin{array}{l}\text { Female } \\
\mathrm{n}=32\end{array}$ \\
\hline Risk & 18 & 6 & 12 & 9 & 9 & 7 & 11 \\
Risk-Fr & 14 & 6 & 8 & 10 & 4 & 6 & 8 \\
Risk-Se & 49 & 22 & 27 & 24 & 25 & 21 & 28 \\
Risk-Oth & 1 & 0 & 1 & 1 & 0 & 0 & 1 \\
Help-Se & 33 & 15 & 18 & 18 & 15 & 15 & 18 \\
Help-Oth & 2 & 1 & 1 & 2 & 0 & 2 & 0 \\
Help-In-Ac & 23 & 6 & 17 & 13 & 10 & 11 & 12
\end{tabular}


Table E-2: Frequency of Codes Mentioned Concerning the Problems Associated with Drug Use for Fourth and Eleventh Grade, Caucasian and African American, and Male and Female Respondents.

\begin{tabular}{lccccccc} 
CODE & Total & 4 th & 11 th & Cau & AA & Male & Female \\
\hline Harm-Phy-S & 29 & 14 & 15 & 14 & 15 & 17 & 12 \\
Harm-Phy-O & 5 & 1 & 4 & 3 & 2 & 2 & 3 \\
Harm-Em-S & 20 & 7 & 13 & 13 & 7 & 12 & 8 \\
& & & & & & & \\
Harm-Em-O & 5 & 1 & 4 & 1 & 4 & 3 & 2 \\
Harm-Soc & 0 & 0 & 0 & 0 & 0 & 0 & 0 \\
Drug-Path & 42 & 22 & 20 & 22 & 20 & 22 & 22 \\
Drug-Freq & 35 & 19 & 16 & 17 & 18 & 17 & 18 \\
Drug-Rat & 3 & 0 & 3 & 2 & 1 & 2 & 1
\end{tabular}


Table E-3: Frequency of Codes Mentioned Concerning the Treatment of Users and Dealers for Fourth and Eleventh Grade, Caucasian and African American, and Male and Female Respondents.

\begin{tabular}{|c|c|c|c|c|c|c|c|}
\hline CODE & $\begin{array}{l}\text { Total } \\
\mathrm{n}=64\end{array}$ & $\begin{array}{l}4 \text { th } \\
n=32\end{array}$ & $\begin{array}{l}11 \text { th } \\
\mathrm{n}=32\end{array}$ & $\begin{array}{l}\text { Cau } \\
n=32\end{array}$ & $\begin{array}{l}\mathrm{AA} \\
\mathrm{n}=32\end{array}$ & $\begin{array}{l}\text { Male } \\
n=32\end{array}$ & $\begin{array}{l}\text { Female } \\
n=32\end{array}$ \\
\hline U-Treat-R & 33 & 14 & 19 & 18 & 15 & 16 & 17 \\
\hline U-Treat-Th & 19 & 10 & 9 & 10 & 19 & 9 & 10 \\
\hline U-Treat-M & 8 & 5 & 3 & 5 & 3 & 2 & 6 \\
\hline U-Treat-Co & 7 & 0 & 7 & 4 & 3 & 4 & 3 \\
\hline U-Punish & 9 & 7 & 2 & 5 & 4 & 8 & 1 \\
\hline U-Pun-Ther & 1 & 1 & 0 & 1 & 0 & 1 & 0 \\
\hline U-Time & 8 & 4 & 4 & 3 & 1 & 4 & 4 \\
\hline D-Treat-R & 6 & 3 & 3 & 6 & 1 & 2 & 4 \\
\hline D-Treat-T & 5 & 2 & 3 & 1 & 4 & 3 & 2 \\
\hline D-Punish & 39 & 17 & 22 & 19 & 20 & 24 & 15 \\
\hline
\end{tabular}

